\title{
Las tejedoras mayas de Guatemala: un proceso activo para la salvaguardia de su patrimonio cultural inmaterial
}

The Mayan weavers of Guatemala: an active process for the safeguarding of their cultural intangible heritage

Salvador Almela, Marta ${ }^{a}$

Abellan Calvet Núriab

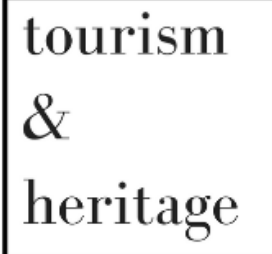

$J O U R N A L$

aAlba Sud - centro de investigación independiente. Barcelona, España. marta@albasud.org

bAlba Sud - centro de investigación independiente. Barcelona, España. nuria@albasud.org

\section{ARTICLE INFO}

Historial artículo:

Recibido 4 agosto 2020

Aceptado 2 octubre 2020

Publicado 5 octubre 2020

\section{Palabras clave:}

Género;

mercantilización;

patrimonio cultural inmaterial; tejedoras mayas; turistificación.

\section{RESUMEN}

Actualmente, muchos son los fenómenos que ocurren alrededor del patrimonio cultural inmaterial (PCI), relacionados con sus políticas y su legado. Con una perspectiva de análisis crítica, este artículo pretende exponer los procesos de patrimonialización, mercantilización y turistificación del PCI, especialmente de los tejidos mayas de Guatemala. La lucha presente de las tejedoras guatemaltecas para proteger y reivindicar el valor cultural de este arte pone sobre la mesa el papel de los distintos actores que intervienen en el patrimonio cultural inmaterial $\mathrm{y}$, de mayor relevancia, las comunidades indígenas. El siguiente marco de análisis sobre las distintas conceptualizaciones de patrimonio, autenticidad, mercantilización y turistificación permitirán entender con mayor profundidad la situación de las tejedoras mayas. La metodología usada en este artículo consiste en un estudio de caso, a partir de la cual se extraen como principales conclusiones la desprotección del PCI de este análisis dadas las complejas definiciones y categorizaciones; la necesidad de identificar las consecuencias de la mercantilización y turistificación de los tejidos ancestrales, recalcando la importancia de la gestión turística desde las comunidades; $y$, finalmente, el protagonismo clave de las mujeres como transmisoras y protectoras del PCI, las cuales han liderado un proceso de lucha y empoderamiento.

\section{ARTICLE INFO}

\section{Article history}

Received 4 August 2020

Accepted 2 October 2020

Published 5 October 2020

\section{ABSTRACT}

Currently, many are the phenomena that occur around intangible cultural heritage (ICH), related to its politics and legacy. With a critical analysis perspective, this article aims to describe the processes of patrimonialisation, commodification, and touristification of ICH, especially of the Guatemalan Mayan fabrics. The ongoing movement 


Keywords:
Commodification;
gender; intangible
cultural $\quad$ heritage;
Mayan weavers;
touristification.

of Guatemalan weavers to protect and vindicate the cultural value of this art brings to light the role of different actors that intervene in intangible cultural heritage and, of greater relevance, indigenous communities. The following analysis framework on the diverse conceptualisations of heritage, authenticity, commodification and touristification allows for a deeper understanding of the Mayan weavers' situation. The methodology used in this article consists on a case study, through which the following main conclusions arise: the lack of protection of ICH of this case study given the complex definitions and categorisations; the need to identify the consequences of commodification and touristification of ancestral tapestries, highlighting the importance of tourism management from the communities; and, finally, the key role of women as transmitters and protectors of $\mathrm{ICH}$, who have headed a process of movement and empowerment.

DOI: $10.1344 /$ THJ.2020.2.7

\section{INTRODUCCIÓN}

El patrimonio cultural inmaterial (PCI) ha sido categorizado por instituciones internacionales como la UNESCO con tal de clasificar este concepto, que a veces puede ser considerado abstracto y confuso. No obstante, el debate sobre la patrimonialización de bienes culturales es muy amplio, teniendo en cuenta los procesos que se producen cuando este se pone en valor. Normalmente, la valorización va acompañada de una mercantilización que agrega capital económico. En muchas ocasiones, los estados y administraciones sacan provecho de la monetización del PCI para impulsar proyectos y campañas turísticas, hecho que, consecuentemente, da lugar a procesos de turistificación.

Por otro lado, también se produce una falta de consideración respecto a los agentes locales que intervienen en esta categorización y producción del patrimonio. Este es el caso de las tejedoras de las comunidades mayas de Guatemala, quienes están sufriendo una desvalorización y banalización de su arte ancestral, acelerada mediante la mercantilización y los plagios de la industria de la moda en el Norte Global. Con el objetivo de revertir esta situación, han empezado un proceso de lucha para reivindicar sus derechos de autor y la propiedad intelectual colectiva, dado que los mecanismos de protección del PCI contemplados en Guatemala no son suficientes. Las tejedoras no solo pretenden que se valoren sus tejidos, sino también mantener el legado, la tradición y la herencia de las mujeres mayas.

En este artículo se expone, en primer lugar, la definición y el marco teórico del patrimonio cultural inmaterial, que engloba diferentes conceptualizaciones como la autenticidad, la identidad, salvaguardia, mercantilización y turistificación. En segundo lugar, a partir de entender la importancia del saber-hacer del arte y de las técnicas del telar de cintura, así como también su interés histórico y simbólico, esta caracterización permite ahondar en el caso de estudio de las tejedoras mayas de Guatemala. Seguidamente se expone el movimiento de las tejedoras para el reconocimiento y la salvaguardia de su patrimonio, que las ha llevado a impulsar un proyecto de ley en favor de la propiedad intelectual colectiva de sus tejidos, con diferentes organismos internacionales implicados. Otra de las preocupaciones de las tejedoras es la mercantilización y la turistificación que sufren por la 
apropiación de su arte por parte de empresas internacionales. Paralelamente, sufren la exotización en el imaginario colectivo de los turistas, alentado por las campañas turísticas del Gobierno y el Instituto Guatemalteco de Turismo (INGUAT). Este caso de estudio muestra el papel clave de las mujeres y el empoderamiento que han liderado para proteger el patrimonio frente a dinámicas globales y locales de menosprecio a su conocimiento y a su patrimonio cultural inmaterial.

\subsection{Conceptualización del patrimonio cultural inmaterial}

La Convención para la Salvaguardia del Patrimonio Cultural Inmaterial de la UNESCO, realizada en 2003, representa la catalogación del mismo concepto. La importancia de esta Convención reside en el hecho de que se define el PCI como "los usos, representaciones, expresiones, conocimientos y técnicas -junto con los instrumentos, objetos, artefactos y espacios culturales que les son inherentes- que las comunidades, los grupos y en algunos casos los individuos reconozcan como parte integrante de su patrimonio cultural". El PCI se cataloga en expresiones dentro de los siguientes cinco ámbitos: a) tradiciones y expresiones orales, incluido el idioma como vehículo del patrimonio cultural inmaterial; b) artes del espectáculo; c) usos sociales, rituales y actos festivos; d) conocimientos y usos relacionados con la naturaleza y el universo; e) técnicas artesanales tradicionales (UNESCO, 2003).

Esta Convención es el resultado de una conceptualización y visibilización progresiva del PCI (Lara, 2017), expresada en diferentes documentos emitidos por instancias gubernamentales encargadas de la elaboración y puesta en marcha de programas para el manejo de las herencias culturales (Sevilla, 2017). Así pues, la asignación de patrimonio cultural de bienes materiales o simbólicos es una construcción social e histórica en la medida en que a ese algo o a ese alguien se le agrega el valor de que debe ser protegido y conservado (Pérez y Machuca, 2017). Esta protección y conservación es definida con el término salvaguardia y deviene el primer objetivo de la Convención. Tal como argumenta Lara (2017), la salvaguardia no consiste solamente en documentar, investigar, catalogar y divulgar el PCI, sino que es necesario fomentar y garantizar la transmisión de la cultura e identidad por parte de los grupos portadores de tradición. No obstante, hay ciertas críticas sobre el desarrollo y la aplicación de las políticas de salvaguardia, ya que la mayoría de países no disponen de los medios humanos ni financieros suficientes y, por otro lado, es difícil conseguir una participación activa de las comunidades en todas las actividades de salvaguardia (Sevilla, 2014).

Los procesos de patrimonialización generan espacios de disputa política, económica y cultural entre todos los actores que participan (Rebollo, 2017), sobre todo cuando han sido usados como un recurso para fortalecer la imagen pública de los gobiernos. De esta manera, las relaciones de poder y políticas nacionales se ven reflejadas cuando el patrimonio es usado en los circuitos mercantiles y los mapas turísticos, gracias al sello de calidad que supone entrar en las listas de la UNESCO (Santamarina y Del Mármol, 2020), así como en la promoción de las prácticas que tienen potencial para proyectar los Estados-nación al extranjero por encima de otras manifestaciones (Villaseñor y Zolla, 2012). De esta forma, la identidad cultural se convierte en una marca que se vende en el mundo globalizado, por lo que deviene un dispositivo de romantización de los pueblos indígenas, ideados para el consumo turístico sin reflexión sobre las verdaderas realidades políticas y sociales (Flores, 
2020). Con este fin se han creado campañas de promoción turísticas en la modalidad de turismo cultural, donde se legitima el patrimonio indígena como una expresión nacional basada en la búsqueda de la raíz identitaria hallada en el pasado de las sociedades prehispánicas, para pasar a ser un bien colectivo en el presente (Lara, 2017).

Consecuentemente, el patrimonio cultural material e inmaterial es puesto en valor en diversos contextos y por diferentes actores (gubernamentales y de la sociedad civil) que aplican estrategias de gestión (planes de salvaguardia, proyectos culturales y artísticos, etc.) para contribuir a la transmisión, protección y conservación del patrimonio (Hernández y Zúñiga, 2017). A pesar de estas políticas, su valorización no es entendida ni propiciada de la misma manera por todas las partes, especialmente si hay intereses comerciales (Chaves, Montenegro y Nova, 2019). La universalidad de la categoría de patrimonio cultural inmaterial para hablar de expresiones particulares ha propiciado que los países signatarios de la Convención de 2003 hayan difundido el concepto en sus respectivos territorios para hacer referencia a una serie de manifestaciones, prácticas, creencias, saberes y costumbres de tipo eminentemente local (Amescua y Topete, 2013). A pesar de enfatizar la diversidad cultural universal, la jerarquización de la UNESCO tiene tendencia a exaltar lo espectacular, lo grandioso, las masterpieces, a través de la noción del Valor Universal Excepcional, por lo que ciertas manifestaciones culturales de carácter inmaterial se pueden ver excluidas (Villaseñor y Zolla, 2012).

Por otro lado, tal como argumentan Kim, Whitford y Arcodia (2019), la UNESCO ha sido criticada por su perspectiva occidentalista a la hora de definir y designar la autenticidad del patrimonio cultural. Desde este punto de vista eurocéntrico, el término folclore se ha utilizado durante mucho tiempo para distanciar la cultura de occidente, entendida como civilizada, del resto de culturas, vistas como primitivas (Rebollo, 2017). Privilegiar las expresiones producidas en ámbitos rurales o indígenas como patrimonio cultural inmaterial es perpetuar la romantización de lo folclórico, y por ende, ahondar en la diferencia de valor entre el patrimonio del Norte Global y el del Sur Global mediante su jerarquización (Villaseñor y Zolla, 2012).

En este sentido, es de especial importancia analizar los distintos niveles de exclusión social que pueden tener lugar a causa de los efectos negativos de las declaraciones de los bienes como PCI, que pueden ser los siguientes: surgimiento de conflictos en el interior de las comunidades; apropiación paulatina de la manifestación cultural por actores ajenos a las comunidades y que pueden terminar representándolas; distribución desigual de las ganancias económicas derivadas de la práctica de la expresión; y su comercialización para la explotación turística y la manipulación política (Sevilla, 2014). Para contrarrestar estos efectos, paradójicamente, muchas comunidades buscan la declaración de su expresión cultural como PCI como estrategia de revitalización o protección, especialmente en aquellos casos donde los gobiernos nacionales suponen una amenaza para su supervivencia (Villaseñor y Zolla, 2012). Poniendo el enfoque en esta problemática, la Convención de la UNESCO de 2003 sobre el PCI propone otorgar un rol más activo a las comunidades, grupos e individuos que crean las expresiones culturales transmitidas de generación en generación, teniendo en cuenta aquel PCI que sea compatible con los instrumentos internacionales de derechos humanos existentes y con los imperativos de respeto mutuo entre comunidades (UNESCO, 2003). 


\subsection{Procesos de mercantilización y turistificación del PCI}

Dado que el patrimonio cultural inmaterial es una práctica social y forma parte de una comunidad que le proporciona un sentimiento de identidad y de continuidad, es cambiante por naturaleza (Bortolotto, 2014; Cejudo, 2014). La dinámica que sigue una tradición es un proceso creativo donde lo recibido es transformado de forma consciente o inconsciente por su receptor (Acuña, 2013) o a partir de los préstamos y adaptaciones de los elementos de otras culturas (Amescua y Topete, 2013). No obstante, a pesar de su modificación, la práctica conserva unos rasgos característicos que la identifican o definen (Acuña, 2013).

Teniendo en cuenta su esencia mudable, resulta imprescindible enfocar el concepto de la autenticidad. En primer lugar, se puede entender desde el punto de vista de la propia práctica cultural, considerando que, a causa del cambio constante del PCI, la autenticidad puede resultar nociva al restringir la plasticidad de la cultura y de sus manifestaciones (Amescua y Topete, 2013). Por otro lado, la mercantilización del patrimonio puede transformarlo y convertirse en una amenaza para sus características y su conservación (Kim, Whitford y Arcodia, 2019). En segundo lugar, se concibe desde el punto de vista del turista o el visitante que entra en contacto con la práctica cultural y, evidentemente, con quien la desarrolla. En este sentido, la industria turística crea expectativas falsas, que tienen el objetivo de convencer al visitante que su experiencia turística del mundo indígena se corresponde con la realidad y satisface su necesidad de autenticidad (Flores, 2014).

Así pues, un aspecto clave y recurrente en el análisis del PCI es el sujeto, es decir, los productores de la manifestación cultural, dado que su indefinición permite que todo individuo, grupo o empresa pueda intervenir en la práctica de expresiones culturales consideradas patrimonio (Sevilla, 2017). De esta forma, se han desmaterializado los productores y el contexto de la manifestación cultural (Montenegro, 2010). Este artículo ahonda en el papel de las comunidades indígenas, a menudo consideradas grupos sociales homogéneos. No obstante, hay que tener en cuenta su complejidad y, por lo tanto, la heterogeneidad de perspectivas y posturas dentro de los mismos grupos, donde las decisiones sobre el uso del PCI inciden de maneras diferentes (Hernández y Zúñiga, 2017).

Con tal de comercializar las expresiones culturales inmateriales, es necesario un primer proceso de mercantilización, es decir, la asignación de un valor económico que las convierte en productos (Cejudo, 2014). En la mayoría de ocasiones, como reflejan varios autores (Hernández y Zúñiga, 2017; Villaseñor y Zolla, 2012), este proceso va acompañado de una oferta y promoción turística que aprovecha la puesta en valor para potenciar dicha industria. De esta forma, se menosprecia su valor social, de memoria, histórico, pertenencia, identidad y cohesión social, entre otros, en beneficio del valor económico (Pérez y Machuca, 2017). Esta publicidad de los pueblos indígenas normalmente se orienta a turistas extranjeros que son atraídos por el exotismo, en lugar de buscar la exploración de las manifestaciones culturales locales (Pereiro, 2013). Esta publicidad se basa en el sesgo de la realidad de las comunidades, dado que no se enseñan aspectos relevantes para comprender el PCI en su globalidad. Se esconden, entre otros, la legitimación de la dominación de los gobiernos mediante no mostrar las condiciones de pobreza y desigualdad de las 
comunidades frente al Estado y a las empresas, o sus luchas sociales, resistencias y formas de autoorganización (Flores, 2014).

La mercantilización del PCI es un fenómeno complejo, por lo que existen múltiples visiones sobre él. Por un lado, se defiende que las identidades de las personas que crean el PCI y el valor simbólico que tiene la manifestación cultural para dicha comunidad se pierden durante el proceso de mercantilización (Prats, 2006; Ypeij, 2012; Zúñiga, 2014); mientras que, por el otro, se sugiere que este proceso conlleva nuevos significados que pasan a formar parte de la cultura local (Ypeij, 2012). Una tercera visión afirma que, con una gestión adecuada, la mercantilización parcial del PCI puede promover que se preserve la manifestación cultural (Cejudo, 2014).

Además de establecer estrategias de gestión, Hernández y Zúñiga (2017) proponen que estos procesos sean llevados por las propias comunidades, quienes decidan qué hacer con su patrimonio, cómo promocionarlo y de qué manera proteger su herencia. De esta manera, la mercantilización del patrimonio podría derivar en procesos de desarrollo, los cuales no se hacen efectivos si el valor recae en los beneficios económicos, en vez de los sociales. La presencia de las comunidades en su propia manifestación cultural y la transmisión generacional de su conocimiento es clave, como se manifiesta en la sentencia "no folklore without the folk" (Kim, Whitford y Arcodia, 2019). No obstante, las manifestaciones culturales están hoy en día muy vinculadas a las lógicas de mercado y a la explotación turística (Sevilla, 2014), la cual fomenta la espectacularización de la diversidad cultural como mecanismo para su venta (Sevilla, 2017).

La transformación de una manifestación cultural en espectáculo, es decir, la teatralización, folklorización o exotización, puede representar una alteración de su función social y simbólica para quedar reducida en un simulacro (Sevilla, 2014); proceso que puede proceder de su turistificación. La mirada turística occidental sobre las comunidades indígenas las reduce a una forma de nostalgia de cercanía con la naturaleza y el medio ambiente, por lo que se las exotiza para satisfacer las expectativas del turista (Pereiro, 2013). Es por eso, que el objetivo debe ser fomentar fórmulas de beneficio económico que repercutan positivamente en las comunidades y refuercen el control colectivo sobre la práctica del PCI, con la prioridad de valorar la propia cultura (Machua, 2017).

\section{METODOLOGÍA Y OBJETIVOS}

Este artículo tiene por objetivo identificar y caracterizar los procesos de patrimonialización, mercantilización y turistificación del patrimonio cultural inmaterial de las comunidades de tejedoras mayas de Guatemala. Con tal de analizar y profundizar en este fenómeno contemporáneo, este artículo se basa en la metodología cualitativa de análisis inductivo del estudio de caso. Se trata, además, de un estudio descriptivo, dado que pretende identificar los elementos clave que inciden en la mercantilización y la turistificación de los tejidos ancestrales de la comunidad maya de Guatemala (Martínez, 2006). El estudio de caso se ha considerado la metodología adecuada dado que se trata de un fenómeno actual, las relaciones entre este y su contexto no son del todo evidentes, y se utilizan fuentes de información diversas (Yin, 1989; citado por Martínez, 2006). 
Para poder contextualizar y entender en profundidad el caso de estudio, ha sido necesario crear una base teórica en relación a conceptos que proporcionan el marco de análisis. Además, debido a la falta de estudios académicos que trabajen en profundidad la situación que viven las tejedoras mayas de Guatemala en relación a la salvaguardia de sus tejidos ancestrales, se he requerido el uso de noticias de prensa con tal de complementar la información.

\section{LAS TEJEDORAS MAYAS DE GUATEMALA: CASO DE ESTUDIO}

Las tejedoras guatemaltecas son las protagonistas de un movimiento por la reivindicación de su cultura, su patrimonio y su arte, como son los tejidos ancestrales que representan su legado pasado, presente y futuro. En este caso, las mujeres luchan contra dinámicas de mercantilización y de apropiación cultural, que se agudizan debido a la llegada del turismo en sus comunidades. En este análisis toman importancia el contexto social y geográfico de las tejedoras; el papel de las mujeres en la transmisión del conocimiento; su rol en los procesos de lucha para reconocer la propiedad colectiva de su arte; y, finalmente, las consecuencias de la comercialización y folklorización del tejido guatemalteco mediante el turismo.

Guatemala es un país que cuenta con aproximadamente 15 millones de habitantes, situado en América Central, limítrofe con México al Norte y al Oeste, Belize al Nord-Este, y Honduras y El Salvador al Sur. Guatemala es uno de los países de América Latina con mayor población indígena, más concretamente, un 43,6\%, identificándose como Maya un 41,7\% de la población (Instituto Nacional de Estadística Guatemala, 2018), a pesar de los siglos de colonización extranjera, las guerras civiles y el paramilitarismo que hicieron disminuir las comunidades originarias del territorio guatemalteco (Méndez, 2018).

\subsection{El telar de cintura y el arte de tejer guatemalteco}

El arte de tejer es una de las tradiciones artísticas de la cultura maya que se sigue ejerciendo actualmente en Guatemala. En este país, se practica el llamado telar de cintura, que es un artefacto de madera con dos extremos, uno de los cuales se liga a un árbol o a cualquier objeto que sujete firmemente, mientras que el otro extremo se enrolla alrededor de la cintura de la tejedora, la cual se sienta sobre sus propias rodillas o en un pequeño taburete (Ypeij, 2012). La importancia de esta práctica cultural radica en la propia producción, ya que juntamente con la agricultura, es uno de los principales pilares de la economía; por lo que es una gran fuente de trabajo, especialmente para las mujeres. De hecho, el aumento de la producción de los tejidos ha provocado el cambio de rol de las mujeres hacia esta actividad en detrimento de actividades realizadas en el campo; aumentando también su capacidad económica (Nelson, 2017). Por otro lado, hay que tener en cuenta su importancia como lugar de memoria que permite la construcción de una identidad colectiva. De esta manera, los tejidos ancestrales se utilizan para almacenar información cultural pero, a la vez, los vestidos mayas, llamados, huipiles, son también los portadores de una historia de exclusión y de resistencia.

Actualmente en Guatemala son mayoritariamente las mujeres indígenas quienes tejen y visten el vestido bordado tradicional en el telar de cintura, por lo que se establecen como 
las transmisoras de la memoria histórica y cultural en resistencia contra las políticas del olvido; uniendo la memoria en Guatemala con la condición de género (Méndez, 2018). El arte de tejer es una tarea normalmente considerada femenina, como lo muestra el presente caso de estudio en Guatemala (Méndez, 2018; Nelson, 2017); así como en Chipre, Europa (Kokko y Kaipainen, 2015); en Cuzco, Perú (Ypeij, 2012); en Grecia, Europa (Bakas, 2017); en comunidades diversas de México como Los Altos de Chiapas (Gil-Corredor, 2017), o Oaxaca (Ojinaga, 2020); la comunidad Seedaq, en Taiwan (Hwang y Huang, 2019); o en Sumba, Indonesia (Untari, Gajjala y Sanjaya, 2020), entre muchos otros.

Por otro lado, hay que tener en cuenta el papel de la mujer como transmisora del patrimonio cultural inmaterial de forma general, en expresiones culturales de categorías diversas (Moghadam y Bagheritari, 2007; Robinson y Barnard, 2007). De esta forma, resulta evidente la relación entre feminidad y supervivencia de comunidad (Bakas, 2007), ya que son las mujeres indígenas quienes mantienen su identidad cultural y la perspectiva de género mediante expresiones culturales y artísticas (Robinson y Barnard, 2007). El vínculo entre artesanías, comunidad y espacio es inherente, ya que son un reflejo de la memoria colectiva que tiene relieve intergeneracional y, por lo tanto, marcan la identidad de los pueblos (Hwang y Huang, 2019).

El movimiento de las tejedoras para el reconocimiento de su propiedad intelectual y los derechos de autor

La lucha de las tejedoras para reconocer su arte se basa en gran parte en la necesidad de reconocer los saber-hacer tradicionales. Siguiendo la definición propuesta por Acuña (2013), estos son un conjunto de conocimientos y saberes humanos que permiten, además del manejo de herramientas y materiales, el desarrollo de secuencias operativas para la obtención de un resultado deseado. Los saber-hacer poseen significación cultural para quien los ejerce, para la comunidad y para los grupos con los que relaciona (Acuña, 2013), por lo que se establecen como una abstracción que debe ser concretada con la finalidad de protegerlos (Montenegro, 2010). Esta protección y preservación va acompañada de una reivindicación del trabajo artesanal y de sus productores en las dinámicas capitalistas actuales (Machuca, 2017). La desaparición de las técnicas tradicionales implicaría la pérdida las habilidades necesarias para crear los tejidos, el conocimiento, la observación y percepción del entorno natural, la estabilidad social, el lenguaje propio de la comunidad o la estabilidad social, entre otros (Ypeij, 2012).

Con el objetivo de salvaguardia de sus tejidos ancestrales, las mujeres tejedoras se han asociado en diferentes organizaciones, asociaciones o movimientos, como es el Movimiento Nacional de Tejedoras Mayas, liderado por la Asociación Femenina para el Desarrollo de Sacatepéquez (AFEDES), que reúne unas 30 organizaciones en 18 comunidades lingüísticas guatemaltecas. En el año 2014, AFEDES inició un proceso de proyecto de ley para el reconocimiento de la propiedad intelectual colectiva de los pueblos indígenas, presentado formalmente el 23 de febrero de 2017 en el Congreso del Estado de Guatemala. Este proyecto de ley responde a la necesidad de llenar el vacío en relación a la regulación de la industria y de la propiedad de las tejedoras sobre su arte ancestral, ya que las protecciones a grupos étnicos establecidas por la Constitución Política de la República de Guatemala son muy limitadas (Picq, 2017). 
Esta propuesta de ley contempla, en primer lugar, la propiedad intelectual colectiva como una resistencia a la usurpación territorial, es decir, al extractivismo del trabajo indígena y de sus saberes ancestrales y fuerza comunitaria. Esta extracción se produce por parte de empresas exportadoras que están explotando el saber-hacer de las tejedoras y lo adaptan a procesos de confección industrial de huipiles, por lo que se amenaza gravemente el conocimiento transmitido de generación en generación. En segundo lugar, la misma ley pretende reconocer a los pueblos indígenas como autores intelectuales, lo que supondría recibir un porcentaje de las ganancias de las corporaciones que se benefician de la exportación de textiles mayas. Actualmente, en Guatemala no se requiere un registro para comprar textiles y diseños de huipiles por parte de empresas, así como tampoco protocolos o procedimientos sobre estas fabricaciones (AFEDES, 2020).

La producción en masa de sus tejidos ancestrales supone grandes diferencias en términos de precios de fabricación y en tiempo; dado que las tejedoras tardan más de tres meses de trabajo y lo venden entre 50 y 250 dólares, mientras que en los telares mecánicos se reduce a la media hora y el precio es de unos 20 dólares (Walsh, 2018). Este hecho repercute indefectiblemente en el precio de venta al público, por lo que este será el único ítem que se tenga en cuenta a la hora de adquirir las piezas si no se conoce ni se entiende su complejo proceso de creación (Kokko, 2015). En otros casos, los diseñadores encarecen el precio de los productos en sobremanera, argumentando la creación de un producto nuevo, lo que se cataloga como una acción de comercio desleal (Argüello, 2020). En ocasiones, los diseños mayas son directamente impresos sobre la tela, reduciendo aún más el precio y el tiempo de confección (Walsh, 2018). Las tejedoras mayas expresan que no perciben ningún beneficio de los intereses comerciales e internacionales por el trabajo y el saber-hacer que se encuentra a las comunidades y es explotado por las empresas exportadoras (Picq, 2017). La falta de regulación de esta industria también ha llevado al empeoramiento de las condiciones de trabajo de las tejedoras, que normalmente se organizan en cooperativas y comunidades, situación que se ve agravada por la dificultad que se encuentran las tejedoras para obtener las certificaciones necesarias del gobierno guatemalteco para exportar sus producciones, mientras que se favorecen las exportaciones de les grandes empresas productoras (Walsh, 2018).

\subsection{La apropiación cultural y la protección de la propiedad intelectual del arte indígena}

Históricamente, la Organización Mundial de la Propiedad Intelectual (OMPI) realizó los primeros intentos de producir un documento internacional para la protección del "folclor" durante las décadas de 1970 y 1980, centrándose en la protección de la propiedad intelectual (Aikawa, 2004). Posteriormente, en 1989, la Conferencia General de la UNESCO adoptó por unanimidad la Recomendación sobre la Salvaguarda de Cultura Tradicional y Popular (UNESCO, 1989), y en 1992 el mismo organismo empezó el programa de Patrimonio Cultural Intangible, siendo la base de muchos de los principios actuales para la salvaguardia de dicho patrimonio (Villaseñor y Zolla, 2012). A pesar de este trabajo, la OMPI y la UNESCO acordaron no incluir gran parte de los aspectos de la propiedad intelectual en la Convención sobre Patrimonio Cultural Inmaterial (Arizpe, 2009). Por este motivo, la resolución y dictamen de normas que protejan los conocimientos tradicionales, que garanticen su utilización en beneficio de las comunidades originales y que desarrollen 
acciones efectivas para su salvaguardia, es aún un aspecto a resolver (Sevilla, 2017). Este hecho también es aplicable al caso de los tejidos mayas de Guatemala, donde los instrumentos internacionales resultan insuficientes.

El vacío legal respecto al derecho de las tejedoras indígenas ha permitido que cualquier persona o empresa transforme los diseños ancestrales en elementos mercantiles diversos, como pueden ser zapatos o bolsas, por ejemplo. Por eso, la comunidad maya guatemalteca denuncia haber sufrido el robo y la apropiación de sus tejidos durante años, tanto por parte de corporaciones extranjeras, como de diseñadores locales no indígenas (Picq, 2017). Al ser una dinámica compartida con otras comunidades de tejedoras de América Central, como Panamá o México, la prevalencia de este tipo de plagio y apropiación cultural dio lugar, en junio de 2017 en Ginebra, a la “34를 Sesión del Comité Intergubernamental sobre Propiedad Intelectual y Recursos Genéticos, Conocimientos Tradicionales y Folclore (IGC)”, comité creado el año 2000 por la OMPI. Este encuentro, donde se reunieron 189 delegados de las comunidades indígenas de todo el mundo tenía por objetivo formar un comité especial dentro de la Organización Mundial de la Propiedad Intelectual para prohibir la apropiación de las culturas indígenas en todo el mundo. (OMPI, 2017).

Las mujeres desafían su exclusión de la esfera pública cuando adquieren responsabilidades por los derechos y por el futuro de sus comunidades a través de la organización y el liderazgo. Por eso, la participación política de las mujeres supone poder redefinir sus roles en las comunidades y superar los estereotipos patriarcales de género. Además, uno de los orgullos de las tejedoras guatemaltecas es haberse empoderado durante este proceso político, que se ha basado en la autoorganización y autogestión (Picq, 2017).

\subsection{La mercantilización y la turistificación del arte indígena}

La vinculación del patrimonio con el turismo equivale a su introducción en el mercado y produce cambios cualitativos en las activaciones patrimoniales y en su evaluación, que pueden repercutir en la construcción contemporánea de la identidad de las comunidades (Prats, 2006). Es precisamente por la enorme incidencia del turismo sobre la salvaguardia del patrimonio, que este es a menudo tratado como una actividad depredadora que no respeta las culturas que lo reciben y que tiene fuertes impactos negativos cultural y socialmente. Entre los cambios que puede provocar el turismo sobre la manifestación cultural se encuentran la modificación de las costumbres y los valores locales, la falta de respeto hacia la comunidad, el enfoque exclusivo hacia el beneficio económico y la categorización de la expresión cultural como espectáculo (Sevilla, 2014). Estas manifestaciones culturales se pueden ver amenazadas por la industrialización y la comercialización globales (Niedderer y Townsend, 2015), que ponen en peligro la autenticidad del patrimonio cultural inmaterial de las comunidades (Kim, Whitford y Arcodia, 2019). En consecuencia, se dificulta la posibilidad de activar el tejido maya como recurso económico para las comunidades indígenas, que impulsaría a la vez el desarrollo local, en favor de su uso turístico.

La mercantilización es una estrategia fundamental de turistificación de expresiones culturales y espacios naturales desde el punto de vista de los gobiernos federales y estatales, con el objetivo de promover el desarrollo turístico sin tener en cuenta los cambios sociales 
que se pueden derivar de esta actividad (Flores, 2014). Georgina Flores (2020) también constata que, algunas veces, el turismo puede aparecer como un agente colonizador que refuerza las relaciones de poder entre los países del Norte y los del Sur Global. A su vez, Zúñiga (2014) expone la importancia de los discursos audiovisuales del turismo con la finalidad de atraer nuevos consumidores mediante la exotificación de las comunidades y la mercantilización de sus expresiones culturales, vaciándolas de su significado y contenido simbólico.

Las secretarías de turismo de los estados han realizado, con una inversión económica importante, diversas campañas promocionales de sus países, donde se incluyen las prácticas culturales, muchas de ellas ancestrales, de los pueblos indígenas (Flores, 2020). En el caso concreto de Guatemala, el Gobierno y el Instituto Guatemalteco de Turismo (INGUAT) utilizan constantemente los textiles y la artesanía indígena para promocionar la actividad turística del país. En la campaña turística del INGUAT “Lecciones de vida”, del año 2015, aparecen diversas mujeres tejedoras y se puede apreciar a un turista adquiriendo las piezas artísticas. En la campaña “Te queremos contar un secreto”, del año 2016, los tejidos ancestrales son usados como fondo de pantalla del eslogan de la campaña. Estas promociones de Guatemala utilizan la imagen de las mujeres indígenas con el huipil realizando tareas de su vida diaria, sin cuestionarse las escasas oportunidades que tienen las mujeres, naturalizando su situación, como afirma la activista de AFEDES Angelina Aspuac (López, 2019).

Por este motivo, las tejedoras expresan sentirse explotadas por las autoridades (CNDH, 2019), dado que no perciben ninguna compensación por el hecho de ser consideradas una de las principales atracciones turísticas del país (Picq, 2017). A parte del malestar generado por no recibir compensaciones económicas, las tejedoras también manifiestan incomodidad por las imágenes de turistas vestidos con sus trajes ancestrales, lo que supone la folklorización de su cultura, por lo que reclaman que el INGUAT destine un porcentaje de los beneficios del turismo para las tejedoras (Felipe, 2016). De hecho, el mismo acto de vestir sus trajes ancestrales es una acción que tiene dos vertientes. En primer lugar, resulta una muestra de resistencia a la substitución de su vestimenta originaria por la indumentaria occidental, decisión que a menudo recae sobre las mujeres de la comunidad (Walsh, 2018). En Guatemala existe una gran presión social para abandonar el uso de los vestidos tradicionales, ya que se consideran antiguos y no son apreciados ni respetados. En cambio, cuando las piezas son vendidas o usadas en entornos del Norte Global, con privilegios raciales y de clase, los tejidos mayas adquieren mayor valor (Afcar Media, 2017). Además, las creaciones de los diseñadores internacionales descontextualizan los tejidos mayas de su significado tradicional y se exponen únicamente como artesanías que obtienen más renombre en los desfiles internacionales de moda (Argüello, 2020). En segundo lugar, el uso de su vestimenta tradicional supone una atracción turística hacia las comunidades, ya que es el reflejo de la mirada romantizada de los turistas (Ypeij, 2012).

\section{CONCLUSIONES}

La complejidad del debate sobre el patrimonio cultural inmaterial muestra cómo las distintas concepciones y categorizaciones realizadas sobre las diversas expresiones culturales no las protegen por completo. Esta diversidad se traslada a los roles de las 
comunidades y los pueblos que crean dichas manifestaciones, que tienen en común el hecho de ser los encargados de mantener vivo el legado y ejercer su salvaguardia. Por este motivo, como defienden Pérez y Machuca (2017), la patrimonialización y las medidas de protección respectivas se deben generar desde espacios sociales, de forma que los propios actores tengan la capacidad, la legalidad, la legitimidad social y el poder para hacerlo. En caso contrario, si el PCI se desvincula de la sociedad que lo produce, este pierde su significado, su funcionalidad y, por lo tanto, su pervivencia (Amescua y Topete, 2013).

En muchas ocasiones, la patrimonialización comporta, seguidamente, procesos de mercantilización que, a la vez, convierten el patrimonio en un objeto de deseo para la industria turística. Actualmente, las culturas de los pueblos indígenas se han integrado a la oferta turística de los destinos a través de una óptica productivista mediante la cual se entiende que el patrimonio también es un producto explotable y rentable económicamente (Flores, 2020). Distintos estudios han demostrado que la implementación de proyectos turísticos que no tiene en cuenta a la población local en la toma de decisiones, refuerza y perpetúa las desigualdades entre los grupos de poder económico y político y la población receptora de los proyectos, situación que se agudiza en el caso de las comunidades indígenas (Flores, 2014).

Esta dinámica se hace patente en la lucha de las tejedoras mayas, donde también se evidencia un racismo latente, tanto institucional como social. A la vez, se muestra la necesidad de una transformación que no cosifique el arte maya, su cultura y su población, sino que reconozca su valor milenario, su complejidad y su riqueza como vínculo cultural entre el pasado y el presente. Para llegar a este escenario es necesario romper con la política vertical que se ha establecido en el ámbito patrimonial institucional, con tal de democratizar los procesos y el reconocimiento de las comunidades indígenas como los agentes adecuados para tomar decisiones y participar en la salvaguardia de sus propias manifestaciones culturales (Flores, 2020). Así pues, deben ser estas comunidades las que tengan la capacidad de decidir a favor o en contra de la apuesta por el turismo con libertad, tras evaluar las consecuencias positivas y negativas de esta actividad.

Como se ha analizado extensivamente, la turistificación de las expresiones de patrimonio cultural inmaterial tiene múltiples y diversas consecuencias. Existe, por un lado, el riesgo de generar dinámicas colonialistas y clasistas, concepciones que surgen de un imaginario colectivo que ha folklorizado las expresiones culturales y las comunidades que las crean. Las consecuencias de esta lectura romantizada y exotizada de las comunidades indígenas a menudo derivan en la banalización de su cultura, por lo que se despojan las manifestaciones culturales de toda su importancia simbólica e histórica. Con tal de revertir estas dinámicas presentes, es necesario que la gestión del turismo se pueda realizar desde las propias comunidades, las cuales, en obtener esta capacidad, pueden generar transformaciones que deriven en un proceso de desarrollo efectivo. De esta forma, además, las comunidades pueden decidir cómo quieren transmitir su propia imagen, a quién dirigirla, cómo quieren ser percibidas, y de qué manera se incorporan en el imaginario colectivo. Así pues, si en vez de poner en el centro el desarrollo económico se da importancia a las comunidades, el turismo puede tener la capacidad de proporcionar un encuentro entre culturas y un espacio de diálogo donde se respete el PCI y sus productores. 
El caso de los tejidos mayas de Guatemala muestra la lucha de las tejedoras para iniciar un proceso de empoderamiento que les permita reforzar su capacidad y su poder para promover también el uso de los tejidos en las comunidades, reforzando su autonomía y control sobre su cultura y patrimonio. El mecanismo para asegurar estos aspectos es la apuesta de las tejedoras mayas por la Ley para el reconocimiento de la propiedad intelectual colectiva de los pueblos indígenas, donde reclaman protección para sus tejidos ancestrales, con importancia histórica y simbólica, y los saber-haceres necesarios para su creación. Así, los derechos de autor se podrían dividir entre la comunidad, quien designaría representantes para negociar con las empresas interesadas en usar sus diseños y para administrar la distribución de los fondos que percibirían las tejedoras, dando a las comunidades la oportunidad de romper con el eterno ciclo de la pobreza y de finalmente reconocer la importancia y el valor del trabajo de las tejedoras (Global Voices, 2017). Por consiguiente, los derechos de autor, la propiedad intelectual y el rol de las comunidades se convierten en cuestiones principales para la evolución de este proceso de lucha y sus estudios futuros.

Actualmente, existen mecanismos y herramientas en favor de los Derechos Humanos de los pueblos indígenas, como el Convenio 169 de la Declaración Universal de Derechos de los Pueblos Indígenas, que permiten a las tejedoras organizarse para una mejor gestión y protección de su patrimonio cultural inmaterial. Moghadam y Bagheritari (2007) sugieren que las convenciones y declaraciones internacionales relacionadas con la cultura, deben dirigirse a los instrumentos de derechos humanos y, con especial atención a la mujer, como por ejemplo la Convención sobre la eliminación de todas las formas de discriminación contra la mujer (CEDAW). Con la vista puesta a una esencial interseccionalidad, no se puede entender la lucha por la protección de los tejidos maya sin la lucha de género, dado que son las mujeres las responsables de la transmisión y protección de dicho patrimonio.

Teniendo en cuenta estas oportunidades y mecanismos de protección, el trabajo de las asociaciones como AFEDES o el Movimiento Nacional de Tejedoras Mayas es imprescindible para la lucha por la dignidad de las tejedoras. El tejido maya, con figuras y signos antiguos, es un arte complejo y significativo para todas las mujeres indígenas, el cual no está hecho únicamente para ser atractivo, sino que pretende reflejar la historia de las comunidades y de los antepasados mayas. Hacer visible este fenómeno también ayuda a romper con la mercantilización, banalización y turistificación que provoca el enriquecimiento de algunas culturas frente a la desaparición de otras, como es en este caso la cultura maya en Guatemala.

Agradecimientos: Este artículo ha sido realizado en el marco del Proyecto "Plataforma de Investigación en Turismo, Derechos Humanos y Equidad de Género" desarrollado por Alba Sud con el apoyo de la Agencia Catalana de Cooperación Al Desarrollo (ACCD) (convocatoria 2019).

\section{REFERENCIAS}

Acuña, P.E. (2013). La preservación de los saber-hacer tradicionales, un reto de continuidad. En H. Topete y C. Amescua (Coords.), Experiencias de salvaguardia del patrimonio cultural 
inmaterial, (p. 119-134). Cuernavaca: Centro Regional de Investigaciones Multidisciplinarias (UNAM).

Afcar Media (2017, Marzo 27). Las indígenas guatemaltecas que pueden revolucionar el mercado textil. Afcar Media. 2 de agosto de 2020. https://afcarmedia.com/2017/03/27/las-indigenas-guatemaltecas-que-puedenrevolucionar-el-mercado-textil/

AFEDES (2020). Asociación Femenina para el Desarrollo de Sacatepéquez. Recuperado de https://mujeresdeafedes.wordpress.com

Aikawa, N. (2004). An Historical Overview of the Preparation of the UNESCO International Convention for the Safeguarding of the Intangible Cultural Heritage. Museum International, 56, (1-2), 137-149.

Amescua, C., y Topete, H. (2013). Introducción. En H. Topete, y C. Amescua (Coords.), Experiencias de salvaguardia el patrimonio cultural inmaterial (p. 11-26). Cuernavaca: Centro Regional de Investigaciones Multidisciplinarias (UNAM).

Argüello, B. (2020). Uso de textiles mayas en moda occidental: ¿apropiación cultural indebida?. Investigación para todos. 13 de septiembre de 2020. http://investigacionparatodos.usac.edu.gt/entrevistas/item/91-textiles-mayas

Arizpe, L. (2009). El patrimonio cultural inmaterial de México: ritos y festividades. México: Miguel Ángel Porrúa.

Bakas, E. (2017). Community resilience through entrepreneurship: the role of gender. Journal of Enterprising Communities: People and Places in the Global Economy, 11, (1), 1-25.

Bortolotto, C. (2014). La problemática del patrimonio cultural inmaterial. Culturas. Revista de Gestión Cultural, 1, (1), 1-22.

Cejudo, R. (2014). Sobre el valor del Patrimonio Cultural Inmaterial: una propuesta desde la ética del consumo. Dilemata, 14, 189-209.

Chaves, M., Montenegro. M., y Nova, G. (2019). Orgullo y prejuicio en la identidad de marca. Club Colombia y la valorización de la producción artesanal indígena. Ciencias Sociales y Humanidades, 6, (1).

CNDH (2019). Argumentos para la Defensa y Protección del Patrimonio Cultural de Pueblos y Comunidades Indígenas y Afrodescendientes en México y América Latina: "La Protección del Patrimonio Cultural como Derecho Colectivo". Recuperado de http://appweb.cndh.org.mx/biblioteca/archivos/pdfs/Argumentos-IndigenasAfrodescendientes.pdf

Felipe, O. (2016, Julio 21). Guatemala: Tejedoras exigen ley sobre textiles artesanales. Tercera Información.

2 de agosto de 2020. 
https://www.tercerainformacion.es/articulo/internacional/2016/07/21/guatemalatejedoras-exigen-ley-sobre-textiles-artesanales

Flores, G. (2020). Patrimonio cultural y turismo ¿cómo enfrentar la mercantilización de la cultura indígena?. En A. Vital (ed.), Diversidades, justicia, democracia, (p. 16-32). Ciudad de México: Coordinación de Humanidades (UNAM).

Gil-Corredor (2017). Proceder artístico agenciado por mujeres: Las tejedoras mayas en Los Altos de Chiapas. LiminaR, 1, (2).

Global Voices. (2017). Tras años de apropiación cultural, tejedoras mayas quieren proteger su patrimonio. 2 de agosto de 2020. https://es.globalvoices.org/2017/10/01/tras-anos-deapropiacion-cultural-tejedoras-mayas-quieren-proteger-su-patrimonio/

Hernández, I., y Zúñiga, F.G. (2017). Patrimonio cultural y desarrollo comunitario. Desafíos para la gestión cultural. En M. L. Pérez y A. Machuca (eds.), La patrimonialización ¿un nuevo paradigma? (p. 101-109). Ciudad de México: Colegio de Etnólogos y Antropólogos Sociales A.C.

Hwang, S., y Huang, H. (2019). Cultural Ecosystem of the Seediq's Traditional Weaving Techniques - A Comparison of the Learning Differences Between Urban and Indigenous Communities. Sustainability, 11, (1519), 1-21.

Instituto Nacional de Estadística Guatemala. (2018). Censo de población de Guatemala. Recuperado de: https://www.censopoblacion.gt/cuantossomos

Kim, S., Whitford, S., y Arcodia, M. (2019). Development of intangible cultural heritage as a sustainable tourism resource: the intangible cultural heritage practitioners' perspectives. Journal of Heritage Tourism, 1-14.

Kokko, S., y Kaipainen, M. (2015). The changing role of cultural heritage in traditional textile crafts from Cyprus. Craft Research, 6, (1), 9-30.

Lara, L. (2017). Comunidades en movimiento. En L. Lara, Comunidades en movimiento. Aproximaciones a la expresión inmaterial del patrimonio cultural (p. 35-82). Ciudad de México: Secretaría de Cultura.

López, E. (2019, mayo 27). Tejedoras rechazan "folklorización y mercantilización" de las mujeres indígenas. Publinews. 2 de agosto de 2020. https://www.publinews.gt/gt/noticias/2019/05/27/tejedoras-rechazanfolklorizacion.html

Martínez, P.C. (2006). El método de estudio de caso. Estrategia metodológica de la investigación científica. Pensamiento \& Gestión, (20), 165-193.

Méndez, M.O. (2018). El telar de cintura, inmanencia itinerante de la memoria. Revista Ístmica, 22, 29-45. 
Moghadam, V., y Bagheritari, M. (2007). Cultures, Conventions, and the Human Rights of Women: Examining the Convention for Safeguarding Intangible Cultural Heritage, and the Declaration on Cultural Diversity. Blackwell Publishing, 59, (4).

Montenegro, M. (2010). La patrimonialización como protección contra la mercantilización: paradojas de las sanciones culturales de lo igual y lo diferente. Revista Colombiana de Antropología, 46, (1), 115-131.

Niedderer, K., y Townsend, K. (2015). Empowering crafts - intangible heritage, women and socially disadvantaged groups. Craft Research, 6, (1), 3-8.

Nelson, R. (2017) The limits of cosmopolitanism: exchanges of knowledge in a Guatemalan volunteer programme. Tourism Recreation Research, 42, (2), 248-257.

Ojinaga, B. (2020). Los hilos de la memoria: tejiendo las narrativas de los centros textiles en México y Perú. H-ART. Revista de historia, teoría y crítica de arte, 6, 42-61.

Picq, M. (2017, marzo 7). Tejedoras mayas proponen ley de propiedad intelectual colectiva. Intercontinental Cry. 2 de agosto de 2020. https://intercontinentalcry.org/es/tejedorasmayas-proponen-ley-de-propiedad-intelectual-colectiva-2/

Pereiro, X. (2013). Los efectos del turismo en las culturas indígenas de América Latina. Revista Española de Antropología Americana, 43, (1), 155-174.

Pérez y Machuca (2017). La patrimonialización ¿un nuevo paradigma?. En M. L. Pérez y A. Machuca (eds.), La patrimonialización ¿un nuevo paradigma? (p. 5-14). Ciudad de México: Colegio de Etnólogos y Antropólogos Sociales A.C.

OMPI. (2017). Comité Intergubernamental sobre Propiedad Intelectual y Recursos Genéticos, Conocimientos Tradicionales y Folclore: Trigésima cuarta sesión. Recuperado de: https://www.wipo.int/meetings/es/details.jsp?meeting id=42302

Prats, L. (2006). La mercantilización del patrimonio: entre la economía turística y las representaciones identitarias. Boletín del Instituto Andaluz del Patrimonio Histórico, 58, 72-80.

Rebollo, M.P. (2017). Valoraciones que viven y conviven en los procesos de patrimonialización de expresiones culturales inmateriales. En M. L. Pérez y A. Machuca (eds.), La patrimonialización ¿un nuevo paradigma? (p. 75-82). Ciudad de México: Colegio de Etnólogos y Antropólogos Sociales A.C.

Robinson, O., y Barnard, T. (2007). 'Thanks, But We'll Take It from Here': Australian Aboriginal and Torres Strait Islander Women Influencing the Collection of Tangible and Intangible Heritage. Blackwell Publishing, 59, (4). 
Santamarina, B., y Del Mármol, C. (2020). "Para algo que era nuestro... ahora es de toda la humanidad": el patrimonio mundial como expresión de conflictos. Chungara Revista de Antropología Chilena, 52, (1), 161-173.

Sevilla, A. (2014). Del ritual al espectáculo. Diario De Campo, (2), 24-31.

Sevilla (2017). Los riesgos de la patrimonialización. Una reflexión. En M. L. Pérez y A. Machuca (eds.), La patrimonialización ¿un nuevo paradigma? (p. 27-32). Ciudad de México: Colegio de Etnólogos y Antropólogos Sociales A.C.

UNESCO. (1989). Recomendación sobre la Salvaguarda de Cultura Tradicional y Popular. Recuperado de: http://portal.unesco.org/es/ev.php$\underline{\text { URL ID }=13141 \& \text { URL DO=DO TOPIC\&URL SECTION=201.html }}$

UNESCO. (2003). Convención para la salvaguardia del patrimonio cultural inmaterial 2003. Recuperado de: $\quad$ http://portal.unesco.org/es/ev.php$\underline{\text { URL ID }=17716 \& \text { URL DO=DO TOPIC\&URL SECTION=201.html }}$

Untari, R., Gajjala, R., y Sanjaya, R. (2020). The making of "asli" Sumba woven cloth: how globalising "intangible heritage" impacts women's roles. Development in Practice, 1-11.

Villaseñor, S., y Zolla, E. (2012). Del patrimonio cultural inmaterial o la patrimonialización de la cultura. Cultura representaciones soc, 6, (12), 75-101.

Walsh, A. (2018, Agosto 8). Cómo las mujeres mayas en Guatemala luchan por proteger sus diseños y su identidad. Open Democracy. 2 de agosto de 2020. https://www.opendemocracy.net/es/como-las-mujeres-mayas-en-guatemala-luchan-porproteger-sus-disenos/

Ypeij, A. (2012). The Intersection of Gender and Ethnic Identities in the Cuzco-Machu Picchu Tourism Industry. Sácamefotos, Tour Guides, and Women Weavers. Latin American Perspectives, 39, (6), 17-35.

Zúñiga, F (2014). Nuevos usos del patrimonio arqueológico del tajín, a través de los procesos de turistificación, mercantilización y espectacularización. Anales de antropología, 48, (2), 151-182. 